\title{
REGIONAL EFFICIENCY DIFFERENCES AND DEVELOPMENT POLICY OF AGRICULTURE IN THE YUGOSLAV REPUBLICS: ESTIMATES FROM PANEL DATA
}

\author{
Richard A. Hofler and James E. Payne*
}

\begin{abstract}
This paper discusses economic development policy in the Yugoslav republics, with particular attention to agricultural production. Previous researchers have suggested that a development strategy of transferring investment resources from the more developed to the less developed republics as well as segmentation of the financial system has resulted in an inefficient allocation and use of resources. Thus we examine the question of efficiency from panel data, using the stochastic production frontier. In addition to analyzing the differences across republics, we also address the differences associated with social versus private modes of organizing production. We find the private sector produces with higher output efficiency than the social sector. Moreover, our findings concur with prior discussions on the economic impact of regional development policy pursued in the Yugoslav republics. Relative to the more developed republics, the less developed republics cannot efficiently utilize the large volume of investment resources allocated by the Federal government.
\end{abstract}

\section{INTRODUCTION}

This paper discusses regional development policy in the Yugoslav republics, with a special focus on agriculture. Though the recent political struggle in Bosnia/Herzegovina continues, this study will provide useful information for those Yugoslav republics that have gained independence. By investigating the past dichotomy between private and social agricultural production, the newly formed independent republics have been provided with useful information for developing agricultural policies. As Boyd (1987) points out, Yugoslavian agriculture provides an excellent framework to analyze the relative performance of private and cooperative socialist modes of organizing production. Indeed, Boyd (1987) undertakes an interesting analysis of the differences in agricultural productivity associated with private and social agricultural sectors. In his study, Boyd draws three conclusions with respect to Yugoslavian agricultural production: (1) the social sector is not inherently inefficient and can perform as well as the private sector: (2) both sectors are responding to the economic policies and environment that exist; (3) the social sector is not incapable of exploiting opportunities that would increase productivity and technological change. Hofler and Payne (1993) extend *Professor of Economics, University of Central Florida, and Associate Professor, Eastern Kentucky University. The authors thank Michael L. Boyd for the provision and detailed description of the data and V. K. Chetty for discussions on the topic. 
the work of Boyd by examining the output efficiency associated with less versus more developed regions. This paper goes one step further by examining output efficiency for each of the eight republics by estimating stochastic production frontiers from panel data. In addition to providing measures of mean output efficiency, we also compare these measures between the private versus social sectors of agricultural production.

Prior studies have examined the issue of efficiency with respect to such a regional development policy. Milanovic (1987) investigates patterns of regional growth in Yugoslavia. Milanovic argues that regional development policy relied upon transfers of investment resources from the more to less developed republics via the central government. The problem with such a development strategy stems from the inability of less developed republics to efficiently utilize relatively large volumes of investment. Bateman et al. (1988) touch on this efficiency question in their analysis of the sources of variation in regional gross material product per capita in twenty-six social sector industries and the effectiveness of development policies in reducing regional income variations. Bateman et al. find the total factor productivity differences between LDR's and MDR's are in large part due to an increasing gap in technical efficiency. Thus, we plan to examine the question of efficiency across eight republics of differing levels of development as well as across different modes of organization of agricultural production.

Our inquiry is of further importance given the economic transition currently taking place in Eastern Europe. Considering the relatively large agricultural sectors, Brooks et al. (1991) highlight the importance of agricultural transition in the overall stabilization and structural adjustments in Eastern Europe. Specifically, Braverman and Guasch (1990) suggest the necessity of decollectivation and the distribution of property rights as well as technological change in order to reduce the high costs of production and to enhance the quality and efficiency in the supply of agricultural products. On the demand side, the liberalization of prices and the removal of food subsidies effectively increase the price of food and thus reduce domestic demand. Moreover, the degree to which agricultural transitions takes place is directly related to the macroeconomic stabilization policies undertaken. The tightening of both fiscal and monetary policy, as well as the devaluation of an overvalued currency, results in a reduction in demand. The higher interest rates, coupled with economic uncertainty, introduce a difficult economic environment for the private sector in particular. The private agricultural sector tends to be poorly capitalized, with limited access to both factor and product markets when compared to the socialist sector. (Lipton and Sachs 1990). ${ }^{1}$

Given the current economic consequences of the transition, Murrell (1991) points to the relevance of studying the extent of technical inefficiency across the private and social sectors. Indeed, if technical inefficiency is found to be more 
prevalent in the socialist sectors, perhaps there is hope for the role of marketdriven reforms to enhance overall efficiency. Thus, the task of our endeavor is to provide empirical evidence on the extent of inefficiencies in the social and private sectors of Yugoslav agricultural production.

Section II of the paper will provide a brief overview of economic development policy in Yugoslavia. Section III entertains the question of measuring efficiency from panel data via the stochastic production frontier. Section IV will present the data, empirical results, and conclusions.

\section{OVERVIEW OF DEVELOPMENT POLICY}

Yugoslavia is heterogenous in its six autonomous republics and two provinces. The sources for such heterogeneity are largely due to historical diversity with respect to ethnic, religious, cultural, and linguistic aspects. These differences between republics have spawned the prevailing civil war and the effective realignment of republican boundaries. Though the current situation deserves immense attention by economists, the current study will focus upon one aspect of Yugoslavian development-the agricultural sector. ${ }^{2}$ However, before exploring the agricultural sector, we need to provide a brief historical foundation with respect to post-World War II economic development policy in Yugoslavia.

There have been essentially three phases in post-World War II Yugoslavian economic development: (1) 1947-1951, (2) 1952-1965, and (3) post-1965. The period 1947-1951 was characterized by central planning along the lines of a command economy. All decisions related to the distribution and allocation of investment resources were made at the federal level. Development policies at the Federal level took precedent over the interests of the various republics. Economic development policy simply followed a path similar to other Eastern bloc countries, namely, rapid industrialization of the economy.

The second period, 1952-1965, allowed for more decentralization of decision making at the firm level. Though this movement towards self-management may appear to have enhanced economic efficiency in the allocation of resources, the federal government still retained complete economic and political control. Under the discretion of the federal government, the General Investment Fund was the centralized source for all investment resources. As pointed out by Bateman, et al. (1988), from the 1950s onward, the federal government was transferring resources to less developed republics. The transfer of investment resources originated from the compulsory contributions made by the more developed republics. Such a transfer was based upon the notion that the interests of individual republics were subordinate to interests of the federal government and the whole of Yugoslavia. 
The development strategy was still one of industrialization, with the agricultural sector a secondary concern.

The post-1965 period was characterized by the Economic Reforms of 1965 . These reforms broadened the role of the market mechanism. They also brought an improvement in the agricultural sector, especially the private sector. However, in order to allow for further decentralization, government investment funds were transferred to commercial banks. As a result, the General Investment Fund was replaced by the Federal Fund for the Accelerated Development of the Less Developed Republics. The overall effect of this decentralization was the shifting of control from the federal level to the republican level.

The 1974 Constitution allowed Republics to be responsible for their respective economic development programs. However, a deterrent for the effective implementation of economic development at the republican level was the regionalization of the banking system. First, banks were not permitted to distribute investible resources to projects outside the region for which the resources (savings) originated. This policy was based on the fear there would be a drain of resources from the weaker, less developed regions to the powerful, more developed regions. Second, the interests of the political representatives on the bank's board dictated the allocation of investible resources, not the expected rate of return on the investment. This segmentation of the financial system effectively prohibited capital to freely flow across Republican boundaries. Such a policy has not increased the economic welfare of the less developed republics but has widened the income inequality between the more developed and less developed republics. Given the evolution of regional development policy in Yugoslavia, we wish to address the question of how efficiently the various republics have utilized resources in the agricultural sector.

\section{MEASURING THE EXTENT OF EFFICIENCY}

Efficiency can be appropriately measured by the application of the stochastic frontier methodology developed by Aigner, Lovell and Schmidt (1977), and then extended into panel data by, among others, Schmidt and Sickles (1984), Battese and Coelli (1988), and Cornwall, Schmidt, and Sickles (1990). ${ }^{3}$ In general form, let

$$
\mathrm{Q}_{\mathrm{it}}=\mathrm{f}\left(\mathbf{X}_{\mathrm{it}}\right)+\mathrm{v}_{\mathrm{it}} \quad \mathrm{i}=1, \ldots, \mathrm{n}
$$

represent a non-frontier production function where $Q_{i t}$ denotes output actually produced by the $\mathrm{i}^{\text {th }}$ firm $(\mathrm{i}=1,2, \ldots, \mathrm{N})$ during the $\mathrm{t}^{\text {th }}$ time period 
$(t=1,2, \ldots, T) ; X_{i t}$ is a (1xk) vector of inputs associated with the $i^{\text {th }}$ firm during the $t^{\text {th }}$ period; and $v_{i t}$ denotes the error term assumed to be independent and identically distributed as $\mathrm{N}\left(0, \sigma_{\mathrm{v}}{ }^{2}\right)$, which represents the accumulated effect of measurement error and individually unimportant variables whose values are uniquely related to the given observation and exogenously shift the function. Following the panel data production frontier literature, the model to be estimated is

$$
Q_{i t}=g\left(\mathbf{X}_{i t}\right)+\epsilon_{i t} \quad i=1,2, \ldots N \text { and } t=1,2, \ldots T
$$

where $\epsilon_{i t}=v_{i t}+u_{i t}$ and $u_{i t}$ denotes the second error component, assumed to be an independent and identically distributed non-positive random variable, defined by truncating at zero a $\mathrm{N}\left(0, \sigma_{\mathrm{u}}{ }^{2}\right)$ random variable. This $\mathrm{u}_{\mathrm{it}}$ error term represents the distance by which actual production falls short of the maximum attainable (frontier) production. Lastly, it is assumed that the two error components, $v_{i t}$ and $\mathrm{u}_{\mathrm{it}}$, are independent of each other and of the input variables in the model. Note several features of (2). First, the deterministic portion of (2) differs from that of (1) because the frontier function is higher than the nonfrontier function. Next, each firm's stochastic frontier, on which it aspires to produce so as to maximize its production, is given by

$$
\mathrm{Q}_{\mathrm{a}, \mathrm{it}}=\mathrm{g}\left(\mathbf{X}_{\mathrm{it}}\right)+\epsilon_{\mathrm{it}} \quad \mathrm{i}=1,2, \ldots \mathrm{N} \text { and } \mathrm{t}=1,2, \ldots \mathrm{T}
$$

where $Q_{a, i t}$ is the maximum attainable output of the $i^{\text {th }}$ firm. Note that equation (3) is not identical to equation (1) because of the difference between the $\mathbf{g}\left(\mathbf{X}_{\mathrm{it}}\right)$ and $f\left(\mathbf{X}_{\mathrm{it}}\right)$ functions.

The central focus in this framework is the difference between each observation's actual output (2) and its frontier output (3) as measured by $u_{i t}$ which can differ across all firms. In other words, the value of $\left|u_{i t}\right|$ represents the reduction in output experienced by the $\mathrm{i}^{\text {th }}$ firm during the $\mathrm{t}^{\text {th }}$ time period due to inefficiency. Larger values for $\left|u_{i t}\right|$ reflect greater inefficiency. A measure derived from the $u_{i t}$ is intuitively clearer. Define the technical efficiency of the $i^{\text {th }}$ firm, denoted $\mathrm{RATIO}_{\mathrm{i}}$, as

$$
R A T I O_{i}=\frac{E\left(Y_{i t}^{*} \mid U_{i} x_{i t} \quad t=1,2, \ldots\right)}{E\left(Y_{i t}^{*} \mid U_{i}=0, x_{i t}, t=1,2, \ldots\right)}
$$

This is the ratio of the $\mathrm{i}^{\text {th }}$ firm's mean actual output across all $\mathrm{T}$ periods divided by that same firm's mean frontier output across all T periods. That is, RATIO $_{i}$ represents the $i^{\text {th }}$ firm's mean ratio of actual output to frontier output during the 
time period. RATIO $_{\mathrm{i}}$ takes values between zero and one, with smaller values reflecting greater inefficiency. Battese and Coelli (1988) show that, when the production frontier is defined in terms of the logarithm of output, a consistent estimator of (4) is given by

$$
\operatorname{RATIO}_{i}=\left\{\frac{1-\Phi\left[\sigma_{*}-\left(M_{i}^{*} / \sigma_{*}\right)\right]}{1-\Phi\left(-M_{i}^{*} / \sigma_{*}\right)}\right\} \exp \left(-M_{i}^{*}+\frac{1}{2} \sigma_{*}^{2}\right)
$$

where $\Phi$ represents the distribution function for the standard normal random variable, $\sigma_{*}{ }^{2}$ is the variance of the error term $\epsilon=\mathrm{v}+\mathrm{u}$, and $\mathrm{M}_{\mathrm{i}}{ }^{*}$ is

$$
M_{i}^{*} \equiv\left(-\sigma^{2} \overline{E_{i}}+T^{-1} \mu \sigma_{v}^{2}\right)\left(\sigma^{2}+T^{-1} \sigma_{v}^{2}\right)^{-1},
$$

where

$$
\begin{gathered}
\overline{E_{i}} \equiv T^{-1} \sum_{\mathrm{i}=1}^{T} G_{i_{t}} \\
1 n L_{i}=\left(-T_{i} / 2\right) \ln (2 \pi)-\frac{1}{2} \ln 2-\left(T_{i} / 2\right) 1 n \sigma_{v}^{2}+\frac{1}{2} 1 n\left(1+\lambda T_{i}\right) \\
+\frac{1}{2}\left(1 / \sigma_{v}^{2}\right)\left[\lambda /\left(1+\lambda T_{i}\right)\right]\left[\Sigma_{\mathrm{t}}\left(\varepsilon_{i t}-\mu / \sigma_{v}\right)\right]^{2} \\
-\left(1 / \sigma_{v}^{2}\right)\left[\Sigma_{t}\left(\varepsilon_{i t}-\mu\right)^{2}\right] \\
+\ln \Phi-\left[\lambda /\left(1+\lambda T_{i}\right)\right]^{\frac{1}{2}}\left[\Sigma_{t}\left(\left(\varepsilon_{i t}-\mu / \sigma_{u}\right) / \sigma_{v}+\left(\mu \sigma_{u}\right) T_{i}(1-1 / \lambda)\right]\right. \\
-\ln \Phi\left(\mu / \sigma_{u}\right) .
\end{gathered}
$$

The production frontier model in equation (2) can be estimated by maximum likelihood. The log-likelihood function is $\Sigma_{\mathrm{i}} \operatorname{lnL} \mathrm{L}_{\mathrm{i}}$ where $\lambda=\sigma_{\mathrm{u}} / \sigma_{\mathrm{v}}$ and all other symbols have been defined previously.

We follow the work of Boyd (1987) as well as Hofler and Payne (1993) in estimating two sectoral aggregate production functions which control for the impacts of policy, environment, and organization on performance. The time dummy 
variables capture the effect of policy through disembodied technological change. Partitioning into private and social sectors controls for differences in organization. We emulate Boyd (1987) in these two strategies. He accounts for the influences of environment on performance by utilizing three regional dummy variables. This is where we diverge from Boyd (1987) because of our purpose of measuring efficiency with stochastic frontiers. As discussed above, we expect regional and sectoral differences in efficiency (see Boyd 1987). In fact, it is plausible that each of the eight subsamples by region and sector could exhibit different average efficiency levels and different relationships between output and the independent variables. Consequently, we estimate the production frontier in equation (2) on each of the six subsamples by region and sector.

\section{DATA AND HYPOTHESES TESTS}

The data used in this study duplicate those used by Boyd $(1985,1987)$ because he provided us with them. As Boyd (1987) states, the unit of observation is the region, sector, and year. As stated previously, given eight regions, two sectors and twenty-four years, the total number of observations is 384; one-half are in each sector. The production function relates aggregate output to five inputs. The output series was constructed from the gross outputs of thirty-five products. The output measure actually used is the geometric mean of two series: regional-sectoral gross output using 1961-63 national average prices to weight output and using 1977-79 national average prices as weights. Labor is a full-time-male equivalent series. Land is measured in hectares of working land adjusted to account for regional and sectoral fertility differences. Machinery is tractor horsepower available in the region and sector on the first of each year. Fertilizer is measured in tons of chemical fertilizer consumed. Livestock is an aggregate of all cows, pigs, sheep, goats, horses, and chickens in the region on January 1 of each year (Boyd 1987). Table 1 provides a summary of the relative sectoral growth rates with respect to labor, land, and capital productivities. From the table one easily sees that the social sector exhibits higher levels of labor, land, and capital productivities than the private sector.

The analysis proceeds as follows: a stochastic production frontier is estimated on six different data sets, the private sector and social sector for each of the three regions. The Poor region is composed of Bosnia and Herzegovina, Kosovo, Macedonia, and Montenegro. The Pannonian region consists of Croatia and Voivodina. The Mixed region is made up of Slovenia and Serbia Proper. The measure of the extent of output efficiency for each observation, the ratio of the actual output over frontier output, is then calculated. 


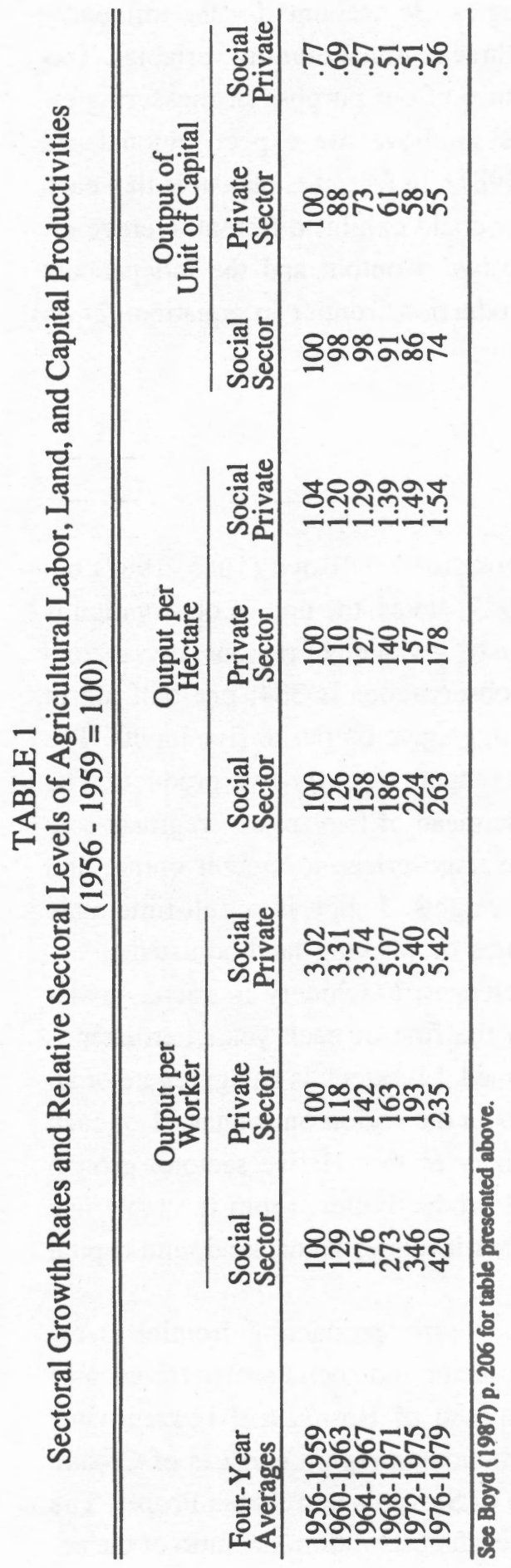


Table 2 displays the estimated frontiers for the private and social sectors in each of the regions. The frontier results for the six models look reasonable. The adjusted $R^{2}$ values range from .88 to .98 and the overall F-statistics are significant. ${ }^{4}$ The Poor Region finds all of the inputs are correctly signed and significant for the private sector, while the social sector yields only the machinery input significant and correctly signed. However, for the Pannonian Region, both the private and social sectors yield significant and correctly signed coefficients on the input variables. The Mixed Region finds that the machinery input is insignificant in both the private and social sectors. In addition to the insignificance of the machinery input, both the livestock and fertilizer inputs are insignificant in the private sector. All the significant coefficients are correctly signed. Notice that the private sector for both the Poor and Pannonian Regions yield the time trends for 1966-1972 and 1973-1979 negative and significant, suggesting a decline in the growth in technological change, whereas the social sector has experienced an increase. This finding concurs with the results of Boyd in that the social sector has received more favorable policy treatment than the private sector.

Based on the frontier estimates derived from Table 2, Table 3 presents measures of mean output efficiency in percentage terms. In the Poor Region each republic in the private sector exceeds its social sector counterpart with respect to mean output efficiency. Likewise, this result holds in both the Pannonian and Mixed Regions. Another observation is that across both the private and social sectors the republics comprising the Poor Region have lower mean output efficiency measures relative to their counterparts in the Pannonian and Mixed Regions. These findings at the republican level concur with the results reported by Hofler and Payne (1993) at the regional level. The measure of mean output efficiency, based on panel data estimation of the stochastic production frontier, supports previous inquiries into the development policy fostered in Yugoslavia.

\section{CONCLUDING REMARKS}

This paper has attempted to explore several aspects associated with the impact of regional development policy in Yugoslavian agricultural production. The first task of this paper was to examine the efficiencies of the private and social sectors of Yugoslavian agriculture across the six republics and two provinces. In examining the question of efficiency via the technique of the stochastic production frontier, we find that the private sector produces with higher mean output efficiency than the social sector. This result differs from Boyd (1987) in part due to the implementation of a more appropriate method for measuring efficiency. 


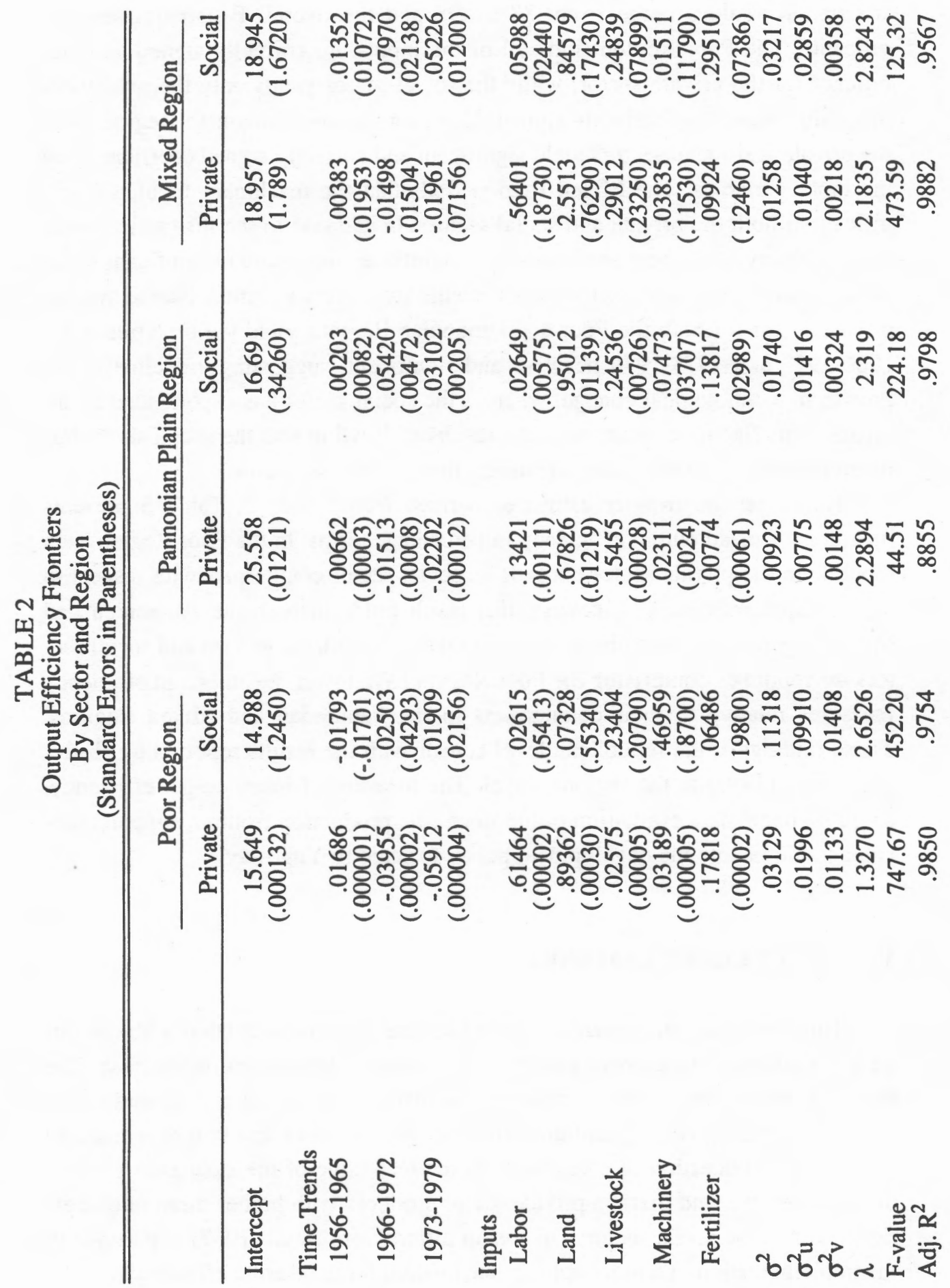




\section{TABLE 3}

Mean Output Efficiency Measures

(Ratio of Actual to Frontier Output)*

\begin{tabular}{lcc}
\hline & Private Sector & Social Sector \\
\hline Poor Region & .965620 & .923486 \\
Bosnia/Herzegovina & .957898 & .913337 \\
Kosovo & .964283 & .953515 \\
Macedonia & .961745 & .832122 \\
Montenegro & & \\
& & \\
Pannonian Region & .966320 & .962859 \\
Croatia & .966237 & .963165 \\
Voivodina & & \\
& & .962127 \\
Mixed Region & .966774 & .961314 \\
Serbia Proper & .965936 & \\
Slovenia &
\end{tabular}

*Values range from 0 to 1 , with a value of 1 denoting $100 \%$ output efficiency.

The second task was to investigate regional efficiency differences as a continuation of the work of Milanovic (1987) and Bateman et al. (1988), as well as Hofler and Payne (1993). We address the second issue of regional efficiency differences by analyzing the output efficiency at the republican level as well as across private and social sectors. From the efficiency measures reported, the republics in the Pannonian and Mixed Regions appear more efficient than the republics comprising the Poor Region in the case of both the private and social sectors. These regional findings seem to concur with Milanovic's (1987) study of regional growth and development policy. Milanovic argues that less developed republics could not efficiently utilize the large volume of investment resources allocated from the more developed republics via the central government.

We next extend Milanovic (1987) and Bateman et al. (1988) by delving deeper into the nature of regional efficiency differences. This is accomplished by comparing the mean output efficiencies of the three regions in both the private and social sectors. As we mentioned before, the Poor Region is the least efficient in both sectors. However, unlike the findings of Hofler and Payne (1993), we find 
that Slovenia and Serbia Proper are not more output efficient than Pannonia in the social sector. Yet, these two regions appear equally efficient in the private sector.

These results give us insight into the overall regional efficiency differences. First, it seems that the Poor region is uniformly the least efficient region, regardless of the sector. Second, regardless of the level of development of the republic, the private sector yields higher mean output efficiency measures than the social sector. Finally, though this paper focused upon the econometric estimation of output efficiency measures, the results provide some suggestions for economic policy reforms. In the case of Yugoslavian agriculture, the empirical evidence reported suggests greater liberalization of the market mechanism. As advanced by Murrell (1991), more effective allocation of factor inputs as well as financial resources could enhance agricultural efforts. Given the time frame analyzed (1955-1979), private agricultural production faced two constraints: (1) number of hectares of land and (2) number of non-family members to work on the farm. Note that even with these constraints, the private sector yielded higher mean output efficiency measures than its social sector counterpart. Thus, relaxing these constraints and allowing the private sector to exploit possible economies of scale may enhance efficiency.

\section{ENDNOTES}

1. The Fall 1991 issue of the Journal of Economic Perspectives provides an excellent symposium on the economic transition in the Soviet Union and Eastern Europe. In particular, the article by Brooks et al. (1991, pp. 150-160) outlines a detailed step-by-step framework for agricultural transition.

2. For a historical as well as current economic and political environment prevailing in Yugoslavia, consult Horvat (1971), Sapir (1980), Gapinski, et al. (1989), and Payne (1991).

3. Aigner, Lovell and Schmidt (1977) estimate two stochastic frontier (ALS) models by ML with two one-sided error specifications: half-normal and exponential. The results are virtually identical coefficient, variance and incidental parameter estimates. Cowing, Reifschneider and Stevenson (1983) also estimate two ALS models by ML with two one-sided error specifications: truncated normal and exponential. They find virtually identical coefficient, variance and incidental parameter estimates.

4. The adjusted $R^{2}$ and F-statistics are reported from an OLS step used to obtain start values for the ML step. 


\section{REFERENCES}

Aigner, D.J., C.A.K. Lovell, and P.J. Schmidt. "Formulation and Estimation of Stochastic Frontier Production Function Models." Journal of Econometrics 6, no. 1 (July 1977): 21-37.

Bateman, Deborah A., Mieko Nishimizu, and John M. Page, Jr."Regional Productivity Differentials and Development Policy in Yugoslavia, 1965-1978," Journal of Comparative Economics 12 (1988): 24-42.

Battese, George E., and Timothy J. Coelli. "Prediction of Firm-Level Technical Efficiencies with a Generalized Frontier Production Function and Panel Data." Journal of Econometrics (1988): 38, 387-399.

Boyd, Michael L. The Comparative Performance of Social and Private Organization: The Case of Postwar Yugoslav Agriculture, unpublished Ph.D. Dissertation, Stanford University, 1984.

Boyd, Michael L. "The Effect of Policy on System Performance: The Case of Yugoslav Agriculture." Comparative Economic Studies, 27 (Summer 1985): $1-23$.

Boyd, Michael L. "The Performance of Private and Cooperative Socialist Organization: Postwar Yugoslav Agriculture." Review of Economics and Statistics (1987): 205-214.

Bravernman, A., and J.L. Guasch. "Agricultural Reform in Developing Countries: Reflections for Eastern Europe." American Journal of Agricultural Economics (December 1990): 1243-1251.

Brooks, Karen, J., Luis Guasch, Avishay Bravermann and Csaba Csaki. "Agriculture and the Transition to the Market." Journal of Economic Perspectives 5, no. 4 (Fall 1991): 149-161.

Cornwell, Christopher, Peter Schmidt, and Robin Sickles. "Production Frontiers with Cross-Sectional and Times Series Variation in Efficiency Level." Journal of Econometrics 46 (1990): 185-200.

Cowing, Thomas, D. Reifschneider, and R. Stevenson. "A Comparison of Alternative Frontier-Cost Function Specifications." Chapter four in Developments in Econometric Analysis of Productivity: Measurement and Modeling Issues Boston: Kluwer-Nijhof Publishing, 1983.

Gapinski, James H., Borislav Skegro, and Thomas W. Zuehlke. "A Model of Yugoslav Economic Performance." Journal of Comparative Economics 13 (1989): 15-46.

Hofler, Richard A., and James E. Payne. "Efficiency in Social Versus Private Agricultural Production: The Case of Yugoslavia." Review of Economics and Statistics 75, no. 1 (1993): 153-157. 
Horvat, Branko. "Yugoslav Economic Policy in the Post-War Period: Problems, Ideas, Institutional Developments." American Economic Review 61 (1971): 69-169.

Jondrow, J., C.A.K. Lovell, I. Materov, and P. Schmidt. "On the Estimation of Technical Inefficiency in the Stochastic Frontier Production Function Model." Journal of Econometrics (August 1982): 233-238.

Lipton, David, and Jeffrey Sachs. "Creating a Market Economy in Eastern Europe: The Case of Poland." Brookings Papers on Economic Activity 1, no. 2 (1990): 75-133.

Milanovic, Branko. "Patterns of Regional Growth in Yugoslavia, 1952-1983." Journal of Development Economics 25 (1987): 1-19.

Murrell, Peter. "Can Neoclassical Economics Underpin the Reform of Centrally Planned Economies?" Journal of Economics Perspectives 5. no. 4 (1991): 59-76.

Nishimizu, Mieko, and John Page. "Total Factor Productivity Growth, Technological Progress and Technical Efficiency Change: The Dimensions of Productivity Change in Yugoslavia, 1965-1978." The Economic Journal (1982): 920-936.

Payne, James E. "Yugoslav Price Inflation: An Empirical Investigation." Journal of Developing Areas 25 (April 1991): 395-404.

Sapir, Andre. "Economic Growth and Factor Substitution: What Happened to the Yugoslav Miracle?" Economic Journal 90 (June 1980): 294-313.

Schmidt, Peter, and Robin Sickles. "Production Frontiers and Panel Data." Journal of Business and Economic Statistics 2 (1984): 367-374.

Weinstein, M.A., "The Sum of Values from a Normal and a Truncated Normal Distribution." Technometrics 6 (1964): 104-105. 